\title{
DISCRIMINAÇÃO DE GÊNERO E DIREITOS FUNDAMENTAIS: DESDOBRAMENTOS SÓCIO- HISTÓRICOS E AVANÇOS LEGISLATIVOS
}

\author{
GENDER DISCRIMINATION AND \\ FUNDAMENTAL RIGHTS: SOCIO-HISTORICAL \\ DEVELOPMENTS AND LEGISLATIVE PROGRESS
}

Taylisi de Souza Corrêa Leite

Paulo César Corrêa Borges

Euller Xavier Cordeiro

\section{RESUMO}

Por meio dos contornos históricos e sociológicos do gênero, torna-se possível compreender a evolução de garantias jurídicas positivadas como produtos de intensas lutas feministas, inseridas na dinâmica dos conflitos sociais que marcaram a modernidade recente. Porém, é patente que a positivação de direitos é insuficiente para concretizar a igualdade de gênero numa sociedade cujos valores machistas têm profundas raízes na formação cultural de todo o mundo ocidental. Preconizando-se que apenas uma concepção pós-estruturalista de gênero como pauta do feminismo é que pode garantir uma real emancipação subjetiva da mulher na atualidade, intenta-se demonstrar que as garantias legais e sua evolução passam por um substrato teórico acerca das concepções sobre gênero. A partir de uma análise da evolução dos direitos das mulheres, especialmente no Brasil, este trabalho pretende lançar luzes para a edificação de uma nova visão acerca dos direitos da mulher como direitos fundamentais, superando o abismo entre garantias legais e sua efetividade.

Palavras-chave: Gênero. Feminismo. Direitos da mulher. Brasil. Direitos humanos. 


\section{ABSTRACT}

Through the historical and sociological contours of the genre it becomes possible to understand the evolution of legal guarantees as products from feminist struggles, embedded in the dynamics of social conflicts that marked the late modernity. However, it is clear that the positiveness of rights is insufficient to achieve gender equality in a society whose sexist values have deep roots in the cultural formation of the western world . Advocating that just a poststructuralist conception of gender as feminist agenda is that it can ensure real subjective emancipation of women today attempts to demonstrate that the legal guarantees and evolution go through a theoretical background about the conceptions of gender. From an analysis of the evolution of women's rights, especially in Brazil, this paper aims to shed light to the building of a new vision of women's rights as fundamental rights, overcoming the gap between legal guarantees and their effectiveness.

Keywords: Gender. Feminism. Women's rights. Brazil. Human rights.

\section{INTRODUÇÃO}

Sempre que se trata de processos discriminatórios, há uma perversidade inerente à sua dinâmica, que insiste em negar sua existência concreta. Por subterfúgios, como a piada ou escamoteamentos mais diversos, a sociedade não escancara a discriminação. Por isso, o primeiro desafio para a superação da exclusão e afirmação de direitos consiste no escancaramento das demandas. No Brasil, isso é ainda mais contundente, tendo em vista nossa mitografia democrática, calcada nas fantasias da cordialidade e do pacifismo, e mascarada na veleidade dos tratamentos.

É patente que nenhuma prática discriminatória está fundamentada em diferenças biológicas efetivamente. Na realidade, tomam-se por subterfúgio alguns marcadores físicos e/ ou culturais para se constituir uma diferença sociocultural, ou seja, não é a biologia que estabelece o parâmetro discriminatório - ela apenas funciona como mais um elemento tomado para se erigirem padrões de normalidade e aceitação, subjugação e empoderamento. No caso das mulheres, a diferença biológica é bastante significativa e, especialmente pelas demandas relacionadas 
com a sexualidade, tem servido para constituir espaços sociais que a mulher pode ou não pode ocupar desde os tempos mais remotos.

As práticas de subjugação da mulher remontam à Antiguidade e perduram até os dias presentes, apesar de a modernidade capitalista esclarecida ter prometido igualdade. Embora lutas sociais, principalmente, durante o século $X X$, tenham encontrado êxito relativo no que diz respeito à positivação jurídica de direitos da mulher, como a própria declaração de 1948 e as convenções internacionais, as construções simbólicas que perfazem a cultura das relações intersubjetivas continuam situando a mulher no lugar da subjugação.

A despeito dos direitos positivados em documentos legislativos mais diversos, a exclusão persiste, e a perversidade das imposições culturais mina qualquer possibilidade concreta de dignidade humana feminina. Nesse sentido, as garantias positivadas e a evolução legislativa precisam acompanhar o desenvolvimento histórico-social e corresponder aos anseios das mulheres na construção de sua dignidade e dos direitos humanos.

Por esse descompasso entre as garantias formais e os direitos subjetivos positivados na forma jurídica com relação à sua efetividade na proteção à mulher, este texto tem por objeto a correlação entre as estruturas simbólicas e axiológicas que suportam historicamente o sexismo e a positivação de direitos das mulheres no Brasil, decorrente das lutas sociais dos movimentos feministas.

Nossa hipótese é a de que, diante das estruturas jurídicas da modernidade, para que um sujeito de direitos possa concretamente se apropriar de bens jurídicos materiais e imateriais, o que inclui os conteúdos dos direitos fundamentais, é preciso, antes, que seja reconhecido como sujeito. Diante de uma racionalidade falocêntrica que identifica o sujeito apenas como um sujeito masculino, ${ }^{1}$ ainda que formalmente as declarações de direitos humanos e as constituições dos países democráticos propugnem igualdade, esta jamais será alcançada se a mulher permanecer vista como algo, e não como alguém.

Desse modo, os direitos das mulheres podem e devem ser positivados, mas a luta do feminismo jamais pode se contentar com sua previsão formal. Ainda, a percepção do que é ser mulher e qual lugar ocupa na estrutura social da modernidade capitalista deve ser olhada 
com cautela. Os marxismos tradicionais costumam priorizar as grandes categorias para dar conta dos processos de desigualdade, de modo que o dístico da luta de classes acaba por olvidar questões relacionadas com estigmas de subjugação, como o racismo e o machismo. Tratar a mulher a partir de um olhar marxista tradicional já não nos parece o mais adequado para uma abordagem profunda sobre a temática.

Por essa razão, como referencial teórico de sustentação de nosso argumento hipotético, trouxemos autoras que trabalham com uma perspectiva pós-estruturalista de gênero, a fim de não recair nas armadilhas da universalização subjetiva e das grandes categorias metafísicas que não têm ressonância em pessoas reais. Conquanto, isso não significa que abrimos mão do materialismo dialético para compreender a história dos direitos das mulheres.

Com essa perspectiva, queremos mostrar que não há apenas uma mulher, mas muitas possibilidades de ser mulher e se saber mulher, de modo que o direito, que opera tradicionalmente com universais, precisa ser permeado dialeticamente por particularidades. Para nós, essa é a única forma de efetivar direitos das mulheres, desde que um novo olhar cultural se fortaleça, dissociado de qualquer perspectiva de inferiorização e reificação do feminino.

\section{ASPECTOS HISTÓRICOS E SOCIOLÓGICOS DA LUTA FEMINISTA}

Podemos dizer, didaticamente, que o feminismo ocidental é sociologicamente dividido em três grandes gerações. Na primeira geração do feminismo, o objeto primordial das lutas por igualdade refere-se ao direito de votar, de ser proprietária, de realizar contratos e ao direito da mulher em escolher o homem com quem iria dividir a vida, escapando das imposições patriarcais e dos casamentos arranjados. As sufragistas ou sufragetes do Reino Unido e dos Estados Unidos da América ficaram conhecidas por sua luta civil, que contrariava a crença pseudorracional fundada em autores modernos de que a mulher era incapaz de tomar decisões argutas para reger sua vida patrimonial e os destinos republicanos. Ao fim, conseguiram chamar a atenção dos políticos varões por meio de atos extremos, como tentativas de suicídio e, após de uma luta dolorosa e árdua, obtiveram algum êxito. Diz 
Leda Maria Hermann que "A efervescência dos ideais democráticos no século XIX fez da batalha pelo direito ao voto o impulso fundamental dos movimentos das mulheres. Equiparadas aos doentes e deficientes mentais e às crianças, as mulheres eram consideradas intelectualmente incapazes de exercer direitos políticos". ${ }^{2}$

Assim, a estratégia de luta mais eficaz é também a mais extrema. A primeira conquista parcial das mulheres ocidentais deu-se após a morte de uma manifestante que se atirou à frente do cavalo do rei da Inglaterra. A partir de então, com a aprovação do Representation of the People Act, em 1918, estabeleceu-se o voto feminino no Reino Unido, definitivamente impulsionado pela luta social da primeira onda do feminismo. $\mathrm{O}$ advento da lei britânica motivou mulheres de diversos outros países a lutarem pelo sufrágio em todo o Ocidente.

No Brasil, a luta pela emancipação feminina fortaleceu-se no Rio Grande do Norte, após uma mulher conseguir judicialmente o reconhecimento de seu direito de votar, e foi ganhando impulso em todo o País, levando o voto feminino a ser regulamentado em 1934. Nos Estados Unidos da América, a luta foi ainda mais contundente. O primeiro grupo norte-americano organizado era a "Sociedade Antiescravagista Norte-Americana", que tinha por mote principal a luta abolicionista, liderado por Susan B. Anthony, Lucretia Mott, Elisabeth Cady Stanton, Lucy Stone e Frances Wright. Além desta, a luta trabalhista foi crucial. Uma manifestação reprimida com brutal virulência, no dia 8 de março de 1857, matou mais de uma centena de mulheres carbonizadas. Apesar de parecer que o "Dia Internacional da Mulher" é uma dádiva da evolução humana, ele é fundado nesse acontecimento específico, porque simboliza a luta feminina por direitos prometidos nas revoluções burguesas, por meio de sangrentas contendas sociais levadas a cabo por mulheres ocidentais até os dias presentes. Muito diferente do que se propaga, a "evolução histórica" dos direitos da mulher não é mero desdobramento de um processo civilizatório modernizante contínuo. Em 1848, quase uma década antes do episódio na fábrica têxtil, a Convenção de Sêneca Falls já havia discutido a luta por direitos de igualdade de propriedade e salário, guarda dos filhos, autonomia para efetuar contratos e capacidade para ser sujeito processual ativo, além da principal bandeira do movimento: o sufrágio feminino. Em 1869, criou-se a “Associação Nacional para o Sufrágio 
das Mulheres", mas a luta das sufragistas norte-americanas só obteve êxito em 1920, com a Emenda Constitucional n. ${ }^{\circ} 19 .^{3}$

Já a chamada segunda onda do feminismo representa o período da atividade feminista que teria começado no início da década de 1960 e durado até o fim da década de 1980, com o Women's Liberation Front (Frente de Liberação das Mulheres), a queima de sutiãs e os protestos por liberação sexual. Situa-nos Eric Hobsbawm:

[...] a partir da década de 1960, começando nos EUA, mas espalhando-se rapidamente pelos países ricos do Ocidente e além, nas elites de mulheres educadas do mundo dependente - mas não, inicialmente, nos recessos do mundo socialista - encontramos um impressionante reflorescimento do feminismo. Embora esses movimentos pertencessem, essencialmente, ao ambiente de classe média educada, é provável que na década de 1970, e sobretudo na de 1980, uma forma política e ideologicamente menos específica de consciência feminina se espalhasse entre as massas do sexo (que as ideólogas agora insistiam que devia chamar-se 'gênero'), muito além de qualquer coisa alcançada na primeira onda de feminismo. ${ }^{4}$

A nova perspectiva adotada consistia em apartar a mulher de sua identificação necessária com o papel social de guardiã do lar e da família e da obrigatoriedade identitária de ser esposa e mãe para se reconhecer mulher. A mais ilustre representante dessa geração é Simone de Beauvoir, com sua obra emblemática O segundo sexo. Afirma Helio Gallardo:

Podría decirse, em el extremo, que hasta la década de los sesenta el siglo XX parecía dominado y caracterizado por las movilizaciones anticoloniales. Desde los setenta, en cambio, adquirem resonancia y projección las luchas de la mujer com teoría de género y los movimientos ecologistas [...] la vivencia de la opresión de género em la relación de pareja y de família ayudó a descodificar el mundo imperante como un orden generalizado de violaciones e violencias. La dominación patriarcal y masculina agredía desde luego a las mujeres en él ámbito 'íntimo' del hogar [...]. Internalizado el patriarcado por mayorías femeninas [...] hacia verse desde fuera de sí mismas a las mujeres, las llevaba a torturarse, a buscar transformarse (o al menos pretenderlo) en objeto de seducción, de 'encantamiento'. La raíz libidinal de la violencia y sujeción resultó tal vez más vistosa que la tercermundista para trizar la cultura falsamente 
universalista de patriarcas, varones e corporaciones, pero sin conseguir vincularla decisivamente con la dominación geopolítica y económica. ${ }^{5}$

As feministas desejavam obter liberdade para formular qualquer escolha profissional sem serem achacadas por uma sociedade patriarcal tradicionalista, mas era central também a luta pelo reconhecimento da sexualidade feminina, a fim de se romper com a visão tradicional religiosa binária de sexo pecaminoso ou do sexo para procriação. A luta por liberdade sexual significou um ponto fulcral no processo de luta por emancipação feminina, que não está superado - ainda em decurso, mobiliza debates até os dias atuais. É também nesse momento que se inicia o amadurecimento das discussões acerca da discriminação das mulheres, quando o "gênero" vai surgir como uma categoria reivindicada pelo próprio movimento feminista. Afirma Guacira Lopes Louro:

A emergência da categoria [gênero] representou, pelo menos para aquelas e aqueles que investiram na radicalidade que ela sugeria, uma virada epistemológica. Ao utilizar gênero, deixava-se de fazer uma história, uma psicologia, ou uma literatura das mulheres, sobre as mulheres e passava-se a analisar a construção social e cultural do feminino e do masculino, atentando para as formas pelas quais os sujeitos se constituíam e eram constituídos, em meio a relações de poder. O impacto dessa nova categoria analítica foi tão intenso que, mais uma vez, motivou veementes discussões e mesmo algumas fraturas internas. Também as relações de gênero passaram a ser compreendidas e interpretadas de muitas e distintas formas, ajustando-se (a) ou interpelando referenciais marxistas, psicanalíticos, lacanianos, foucaultianos, pós-estruturalistas. ${ }^{6}$

Naquele momento, estabelecer a diferença era estratégico para uma luta por reconhecimento, suplantando a falsa isonomia formal que vigorava desde as revoluções burguesas. Por isso, não sem razão, as feministas da segunda geração buscavam seu referencial teórico nos escritos marxistas.

Ocorre que, com o desenrolar da luta feminista na segunda metade do século XX, outras demandas começaram a surgir, impulsionando os substratos teóricos do feminismo a romper com a categorização marxiana. Epistemologicamente, estudiosas como Judith Butler e Joan Scoth vão procurar ultrapassar as limitações do materialismo histórico, 
entendendo que a análise do sexismo precisava incluir categorias como "classe" e "trabalhador", "homem" e "mulher", numa perspectiva conjunta, suplantando as limitações de uma visão marxista mais ortodoxa, dando origem à categoria sociológica "gênero".

Toda vez que se invoca o "gênero" como uma categoria absoluta, "a priori", está-se cometendo um erro profundo. Embora toda a nossa cultura esteja fundada numa dicotomia entre homens e mulheres, sustentáculo da sociedade patriarcal, os referenciais identitários que separam masculino e feminino, situando cada qual em categorias apartadas e estanques, é um construto sociocultural de salutar importância quando se deseja compreender o fenômeno do sexismo. Nesse passo, a marcação do "gênero", como uma nova possibilidade discursiva emancipatória da subjetividade, é uma tentativa de suplantar a hierarquização. Todas as categorizações desse sistema binário possuem o escopo de situar homens e mulheres em papeis sociais específicos, e esse dualismo que, no Ocidente, remonta à tradição judaico-cristã, não foi alterado na modernidade. Na realidade, a mitificação de um sujeito universal só veio reforçar o não lugar daqueles que não puderam se enquadrar nesse referencial abstrato que suportou toda a positivação moderna de direitos subjetivos. Ensina Lauretis:

A primeira limitação do conceito de 'diferença(s) sexual(ais)', portanto, é que ele confina o pensamento crítico feminista ao arcabouço conceitual de uma oposição universal do sexo (a mulher como a diferençado homem, com ambos universalizados; ou a mulher como diferença pura e simples e, portanto, igualmente universalizada), o que torna muito difícil, se não impossível, articular as diferenças entre mulheres e Mulher, isto é, as diferenças entre as mulheres ou, talvez, mais exatamente, as diferenças nas mulheres. ${ }^{7}$

A partir dessa nova concepção, que traz a diferença para o interior da luta, permite-se uma visão plural acerca das possibilidades de se experienciar o feminino, de ser mulher e se saber mulher.

A modernidade negou subjetividade à mulher, buscando fundamento em discursos biologistas, afeitos à razão, pois já não mais se podia afirmar que a mulher era um ser inferior pela vontade de Deus. A racionalidade moderna não comporta outras mitificações que não 
a de si mesma e, de algum modo, precisava sustentar as teias sociais construídas pela fantasmagoria da religiosidade, enquanto interessantes para a manutenção de estruturas concentradas de poder, de acordo com os interesses do capital.

Ocorre que as dinâmicas relacionais incrustadas no seio social já se pautavam em relações hierárquicas de poder, que passavam também pela diferença de sexo, idôneas a atribuir papeis sociais distintos a homens e mulheres, perfazendo sempre o empoderamento do masculino. Essas dinâmicas remontam à formação moral do Ocidente e foram apreendidas pela modernidade capitalista de forma muito específica, afastando a mulher do patamar de subjetivação universalizante de direitos e da razão, aproveitando-se de sua subjugação cultural para explorar a mão de obra feminina mais drasticamente do que a masculina, e utilizando as investidas psíquicas de necessidade de aceitação pelo masculino para fomentar o consumismo feminino exacerbado.

A despeito de as mulheres ocidentais se julgarem mais avançadas no que diz respeito à efetivação de direitos, garantias e inclusão, deve-se levar em conta a influência do sistema econômico capitalista na dinâmica de sua inserção social. Ainda assim, embora tenhamos significativas conquistas nos âmbitos político e econômico, com mulheres exercendo altos cargos executivos no meio corporativo e munidas de incontestável poder político, como o caso da atual primeira-ministra alemã, da atual presidenta do Brasil e da emblemática "dama de ferro" neoliberal inglesa das décadas anteriores, no desenrolar do trato comezinho, ainda há a mulher para casar e a mulher para fazer sexo (não só no imaginário masculino, tendo em vista que as próprias mulheres são fiscais de um comportamento feminino "adequado").

Por isso, as feministas da contemporaneidade invocam um sujeito do feminino mais abrangente e emancipado, descolado do sexo biológico, para abarcar concepções de gênero amplas e plurais, bem como um patamar de luta menos apartado de uma perspectiva emancipadora do humano. Eis a lição de Teresa de Lauretis, ao propugnar um "sujeito do feminismo":

Com a expressão 'o sujeito do feminismo' quero expressar uma concepção ou compreensão do sujeito (feminino) não apenas como diferente de Mulher com letra maiúscula, a representação de uma essência inerente 
a todas as mulheres [...], mas também como diferente de mulheres, os seres reais, históricos e os sujeitos sociais que são definidos pela tecnologia do gênero e efetivamente 'engendrados' nas relações sociais. ${ }^{8}$

Esse sujeito será constituído discursivamente pelo próprio movimento feminista, ou seja, não pode ser um dado, uma categoria $a$ priori, nem universal, mas deve ser necessariamente uma construção discursiva, o que, também, de maneira nenhuma, pode significar um determinismo linguístico, mas um processo constante de inclusão das diferenças. É a partir dessa revisão categorial e do privilégio da possibilidade de uma construção discursiva que poderemos, então, corroborar um novo sujeito, para que os direitos da humana (mulher) possam finalmente ser efetivados.

\section{Conquistas de direitos das mulheres no Brasil}

Como ocorreu no resto do mundo ocidental, a luta por direitos das mulheres coincide com outros movimentos, como o republicano e o abolicionista; porém, aqui, a positivação normativa se deu de maneira bastante atrasada em relação aos países de capitalismo central. No período colonial, a legislação advinha da metrópole, o que acabou por atrasar o desenvolvimento moderno do direito brasileiro e, consequentemente, a positivação de garantias para as mulheres. Conquanto, mesmo após sua independência, o Brasil permaneceu importando modelos estrangeiros, que não guardavam relação com os aspectos sociais da realidade nacional. ${ }^{9}$ A primeira constituinte, convocada por D. Pedro I, excluía negros e mulheres da condição de cidadãos. Com a proclamação da República, em 1891, essa situação não foi alterada. Se não, vejamos, segundo Cardoso:

A nova Assembléia Nacional Constituinte continuava discriminando as mulheres, os analfabetos, os negros, praças e religiosos. Da mesma forma, o poder econômico continuou sendo abusivo, e os deputados eleitos representavam os interesses dos fazendeiros, da nascente burguesia industrial e financeira, e dos oficiais militares. ${ }^{10}$

O reconhecimento da condição de cidadã e o direito ao sufrágio feminino só vieram em 24 de fevereiro de 1932, desde que a mulher 
fosse casada, viúva ou solteira com renda própria. Em 1934, leciona Silvia Pimentel que essas restrições foram eliminadas e "[...] pela primeira vez, o constituinte brasileiro demonstra sua preocupação pela situação jurídica da mulher proibindo expressamente privilégios ou distinções por motivo de sexo". ${ }^{11}$ A Constituição de 1937 (a "polaca") silenciou sobre o tema, mas, em 1946, a obrigatoriedade em votar foi estendida às mulheres. Em 1962, foi promulgado o "Estatuto da Mulher Casada" (Lei $n^{\circ} 4.121 / 62$ ), que reconheceu sua capacidade civil, a reserva de patrimônio na comunhão de bens e propiciou o "desquite" - já que o Código Civil de 1916 estabelecia ser o homem o "chefe" da sociedade conjugal e, em relação à capacidade, equiparava as mulheres aos silvícolas, menores e pródigos. Com a Constituição de 1967, nossa Constituição pós-declaração da ONU de 1948, foi garantida a igualdade para todos perante a lei, sem distinção de sexo. No dia 18 de dezembro de 1979, foi realizada a Convenção sobre Eliminação de Todas as Formas de Discriminação contra a Mulher, adotada pela Resolução $n^{\circ}$ 341/80 da Assembleia-Geral das Nações Unidas. As determinações dessa convenção objetivavam, clara e primordialmente, a busca da plena igualdade material entre seres humanos do sexo masculino e feminino, não só formalmente perante a lei, mas efetivamente na educação, nos direitos trabalhistas e nos direitos e garantias individuais. Foi ratificada pelo Congresso Nacional brasileiro em 1994.

Então, com a Carta Maior de 1988, foi reconhecido constitucionalmente que a discriminação contra a mulher viola os princípios da igualdade e da dignidade humana, dificultando sua participação na vida política, social, econômica e cultural do País. Posteriormente, tivemos a Convenção de Belém do Pará, em 1994, ratificada pela ordem interna em 1995, que trouxe a definição de violência doméstica contra a mulher, como a que tenha ocorrido dentro da família, em unidade doméstica ou em qualquer outra relação interpessoal, em que o agressor conviva ou haja convivido com a vítima no mesmo domicílio ou comunidade. Ainda reconhece a violência de gênero perpetrada por qualquer pessoa na comunidade, local de trabalho, estabelecimentos educacionais de saúde ou em qualquer outro lugar, mesmo aquela perpetrada ou tolerada pelo Estado.

Contudo, somente 12 anos após a convenção, o Brasil editou uma lei com vistas a coibir concretamente a violência contra a mulher. No 
dia 7 de agosto de 2006, foi publicada a Lei n. ${ }^{0}$ 11.340, uma revolução jurídica na luta pelos direitos das mulheres, que entrou em vigor em 22 de setembro de 2006, alcunhada como Lei Maria da Penha, embora tal denominação não tenha sido feita em seu texto, em homenagem a uma mulher brasileira que sofreu inúmeros abusos e violências de seu companheiro e lutou por obter justiça.

O objetivo primordial da lei é coibir a violência contra a mulher, praticada no âmbito doméstico e/ou decorrente de relações afetivas, recrudescendo o tratamento penal dado ao agressor, que perdeu os benefícios previstos na Lei no 9.099/95. A violência de gênero é, segundo a maioria dos autores, aquela praticada pelo homem contra a mulher, oriunda da desigualdade biológica entre os sexos, porém, mais do que isso, da desigualdade social, que estanca papeis sociais possíveis para seres humanos de um ou outro gênero, que não necessariamente se confunde com o sexo biológico, mas se aproxima das manifestações sociais de papeis femininos ou masculinos.

O masculino define sua identidade social como superior à feminina, estabelecendo uma relação de poder e submissão, que culmina no domínio do corpo da mulher, violentando-o, conquanto, essa percepção esteja profundamente calcada numa perspectiva binária do gênero, que só concebe duas formas de ser e estar no mundo - como homem e como mulher.

Ainda, a Lei "Maria da Penha" (n $\left.{ }^{\circ} 11.340 / 2006\right)$ previu a implementação dos Juizados de Violência Doméstica e Familiar contra a Mulher, com o apoio das equipes de atendimento multidisciplinares. Quase sete anos após a publicação da lei, essa importante política pública é timidamente desenvolvida. Segundo a rede de atendimento à mulher, ${ }^{12}$ há apenas 55 juizados instalados no País e, especificamente no Estado de São Paulo, há somente um na Capital paulista. Dada a complexidade das situações concretas envolvendo as violências contra as mulheres, faz-se imprescindível um atendimento multidisciplinar, para além da parcial perspectiva jurídico-penal. A estruturação dos juizados com a equipe de atendimento multidisciplinar insere-se dentro de uma política de Estado que permite a promoção e a defesa dos direitos humanos das mulheres, num permanente processo de luta por direitos e abertura de espaços. O Estado brasileiro ainda não 
viabiliza a abertura e desenvolvimento dos processos e espaços de luta pela dignidade feminina e a vagarosa criação dos juizados de violência doméstica e familiar contra a mulher com equipes de atendimento multidisciplinar é uma prova disso.

Conforme vimos tentando demonstrar neste trabalho, as generalizações e universalizações acerca do gênero podem constituir um primeiro passo para a positivação de garantias fundamentais, como ocorreu com a lei $\mathrm{n}^{\circ} 11.340 / 06$. Porém, é apenas um primeiro passo. A partir daí, outras batalhas precisam ser travadas, alargando-se a ideia inicial de violência contra a mulher, para novas visões sobre o que pode constituir uma violência de gênero, incluindo-se no rol de proteção, por exemplo, casais homoafetivos que reproduzem os padrões de dominação sexista no interior de seu relacionamento, com uma clara divisão de papeis sociais.

Por isso, enquanto setores conservadores da sociedade insistem em alegar que a edição da lei fere o princípio constitucional da igualdade, membros da magistratura progressista realizam hermenêuticas extensivas da lei, ampliando seu âmbito de aplicação para casais homoafetivos, ${ }^{13}$ para agressores do sexo feminino ${ }^{14}$ e sem vínculo formal com a vítima. ${ }^{15}$

Portanto, sem dúvida, a lei trouxe avanços significativos no combate à violência contra a mulher no Brasil, mas requer implementação completa e efetiva, além de alargamento hermenêutico. Segundo a agência de pesquisas do Senado ${ }^{16}$ - dataSenado - para $60 \%$ das mulheres, a proteção melhorou depois da lei e, para 95\%, uma lei específica sobre o tema é de extrema importância. De 2007 a 2011, a percepção entre as mulheres de que a lei não é respeitada caiu de $49 \%$ para $41 \%$. Obviamente, o caráter preventivo da lei penal tem significativas limitações, de modo que a edição da lei não possui o escopo de acabar com a violência doméstica, porém não se pode negar a necessidade de tratamento criminal diferenciado, pois o Estado não pode se eximir de suas obrigações constitucionais.

Ocorre que a positivação normativa não significa que o texto da lei será integralmente respeitado, muito menos que a violência irá cessar.

Nesse sentido, afirma Maria Berenice Dias: 
Ninguém duvida que a violência sofrida pela mulher não é exclusivamente de responsabilidade do agressor. A sociedade ainda cultiva valores que incentivam a violência, o que impõe a necessidade de se tomar consciência de que a culpa é de todos. O fundamento é cultural e decorre da desigualdade no exercício de poder e que leva a uma relação de dominante e dominado. Essas posturas acabam sendo referendadas pelo Estado. Daí o absoluto descaso de que sempre foi alvo a violência doméstica. ${ }^{17}$

É oportuno frisar, também, que o princípio da igualdade não significa que um Estado democrático constitucional (como o nosso) deva tratar a todos igualmente, pois essa isonomia formal apenas manteria as desigualdades reais. Por isso, o Estado tem a obrigação de promover políticas de isonomia, de modo que o princípio da igualdade é material, corresponde à obrigação estatal de tratar desigualmente os desiguais para promover igualdade. Essa postulação é relevante, pois, quando se editou a Lei $n^{\circ}$ 11.340/06 (Lei Maria da Penha), muitas vozes reacionárias se levantaram, afirmando que os homens também deveriam ter proteção por fidelidade ao princípio da igualdade. Felizmente, esse não foi o entendimento do Pretório Excelso, especialmente no que se refere à inaplicabilidade da Lei $\mathrm{n}^{0}$ 9.099/95. ${ }^{18}$

Mais recentemente, o PLC 122/06,19 em tramitação no Congresso Federal brasileiro, viria, no mesmo sentido, ampliando o rol de tutela da Lei $n^{0} 7.716 / 89$, que só abarca a discriminação racial. Com a alteração, qualquer discriminação em razão de gênero, sexo e orientação sexual, além da raça, seria protegida legalmente. E a proteção é muito específica quando se fala em discriminação: o PLC n ${ }^{0} 122 / 06$ visa a coibir o impedimento de acesso a oportunidades de emprego, estabelecimentos, educação e serviços, em função de discriminação. Trata-se de uma proposta de lei muito específica, que só possui o escopo de atender aos ditames de nossa ordem democrática e da Constituição Federal. Não é nada revolucionário, mas um mero cumprimento da ordem vigente e, ainda assim, encontra tanta resistência. A aprovação do projeto em questão será mais um instrumental na árdua batalha por igualdade e emancipação feminina no Brasil, para que possamos combater a opressão histórica das mulheres e sua exclusão em nossa sociedade. A conversão desse projeto em Lei Complementar é uma agenda de lutas por direitos humanos que a sociedade e, especialmente, os juristas precisam abraçar. 


\section{CONSIDERAÇÕES FINAIS}

A construção teórica de uma concepção de "gênero" que transforma a mulher num sujeito político feminista universal emula os padrões totalitários do esclarecimento, corroborando uma nova excrescência da racionalidade instrumental. Esse sujeito "mulher", como sujeito de direitos, não é capaz de absorver demandas de outros grupos étnicos e culturais que não se coadunem à universalização. As mulheres latino-americanas possuem demandas por direitos muito diversas daquelas das mulheres norte-americanas ou europeias, assim como as mulheres negras possuem questões incompreensíveis para as brancas e as lésbicas reivindicam direitos que não estão na pauta das heterossexuais. Essa concepção particular precisa ser levada em conta num processo de construção de direitos, pelo que as universalizações são maléficas, se tomadas como categorias "a priori".

Então, as universalizações só podem ser vistas como uma plataforma primeva de lutas, uma tela sobre a qual se podem pintar as mais diversas matizes de reivindicações consoantes as especificidades de cada sujeito e as idiossincrasias de cada grupo. É nesse sentido que o movimento feminista atual se pauta numa concepção pós-estruturalista, sem, contudo, criar uma nova categoria universal que inviabilize direitos.

Um feminismo pós-estruturalista precisa, portanto, partir de uma compreensão da constituição identitária do sujeito, compreendendo que a formação subjetiva está pautada em relações de poder, de modo que o escamoteamento das diferenças no interior de cada grupo de gênero (entre "homens" e "mulheres") alimenta essas relações de poder e cristaliza as hierarquias. É justamente essa constituição universal das identidades num sistema binário que suporta a padronização de comportamentos atinentes a um ou outro grupo (isso é coisa de homem, aquilo é coisa de mulher).

Uma concepção verdadeiramente pós-estruturalista precisa desconstruir, inclusive, esses referenciais identitários opressores, subvertendo os padrões para que o sujeito se constitua em sua própria experiência no mundo. Para isso, uma ordem verdadeiramente democrática deve primar para que todas as condições sejam favoráveis a essa 
experiência, permitindo-se a liberdade de escolha, num entendimento amplo acerca da proteção à dignidade da pessoa humana.

É imprescindível, nesse sentido, que os movimentos feministas e os movimentos por direitos humanos realizem um diálogo com a antropologia cultural, segundo a qual a biologia não é um dado determinante, mas, ao contrário, é a cultura que constrói nossa relação com a biologia. Nesse passo, o feminismo pós-estruturalista vai assimilar a compreensão culturalista da civilização, afirmando que o próprio corpo é uma construção cultural e que, num processo emancipatório de gênero, o sujeito precisa ser dotado da liberdade da construção dialética de sua corporalidade.

Ressalte-se que não se refuta a existência do sexo biológico, mas que a identidade de gênero se dê pela introjeção subjetiva das aferições que o sujeito formula acerca de sua própria estrutura corporal, libertando-o dos cerceamentos discursivos exteriores hegemônicos acerca do que é "ser homem" ou "ser mulher".

Por esses contornos, temos duas perspectivas cruciais para a efetivação dos direitos da mulher com máxima eficácia: de um lado, a aplicação enérgica da legislação penal que visa a coibir a violência de gênero, junto com a implementação ampla e eficiente dos postos especializados de atendimento à mulher, que têm previsão legal, mas não se tornaram compromissos de governo, na forma de políticas públicas; de outro lado, a superação cultural da perspectiva binária e dicotômica da existência humana, que separa homens e mulheres e coloca estas últimas em posição subalterna.

A primeira perspectiva tem caráter pós-violatório, isto é, só alcança as demandas quando a mulher já foi violentada. Destarte, apesar de reconhecermos a importância da persecução criminal e do recrudescimento da lei para tutelar os direitos da mulher, temos que este não é o melhor caminho para uma tutela genuína e intergral. $\mathrm{O}$ direito positivo e seus mecanismos vinculantes e sancionadores são salutares, mas não podem ser os únicos. A outra perspectiva privilegia uma proteção pré-violatória, isto é, não cuidar do problema quando ele já ocorreu (por meio de sanção), mas evitar que ele aconteça. Aqui é que entra a revolução cultural propugnada pelo feminismo pós-estruturalista. 
Então, a proposta deste trabalho é que se lute em duas frentes combinadas: numa, pela positivação e efetivação de direitos subjetivos das mulheres e repressão à violência; noutra, pela eliminação cultural de todas as formas de abuso e discriminação. Acreditamos ser possível avançar nos debates acerca dos direitos humanos das mulheres, pois é somente com a garantia e a efetivação dos direitos da humana, isto é, de uma mulher que se saiba mulher por se autorreconhecer como tal pela de sua própria experiência feminina (e de um homem que não se perceba superior à mulher), que, enfim, poderemos erigir uma verdadeira ordem justa e democrática.

\section{NOTAS}

1 A flexão de gênero desse substantivo na língua portuguesa, fazendo-se acompanhar do artigo "o", não é gratuita, denotando a identificação linguística da subjetividade humana, com o "homem", ser humano do sexo masculino.

2 HERMANN, Leda Maria. Maria da Penha Lei com nome de mulher: considerações à Lei $\mathrm{n}^{\circ}$ 11.340/2006: contra a violência doméstica e familiar, incluindo comentários artigo por artigo. Campinas/SP: Servanda Editora, 2008. p. 68.

3 CASTRO, Carlos Roberto de Siqueira. O princípio da isonomia e a igualdade da mulher no direito constitucional. Rio de Janeiro: Forense, 1983. p. 174.

4 HOBSBAWM, Eric. Era dos extremos: o breve século XX - 1914-1991. Tradução de Marcos Santarrita; revisão técnica de Maria Célia Paoli. São Paulo: Companhia das Letras, 1995. p. 306.

5 GALLARDO, Helio. Teoría crítica: matriz y possibilidad de derechos humanos. Cartagena: F. Gómez, 2005. p. 43.

6 LOURO, Guacira Lopes. Epistemologia feminista e teorização social: desafios, subversões e alianças. In: ADELMAN, Miriam; SILVESTRIN, Celsi Brönstrup (Org.). Coletânea gênero plural. Curitiba: Editora UFPR, 2002. p. 15.

7 LAURETIS, Teresa de. A tecnologia do gênero. In: HOLLANDA, Heloisa Buarque de. Tendências e impasses: o feminismo como crítica da cultura. Rio de Janeiro: Rocco, 1994. p. 207.

$8 \quad$ Ibidem, p. 217.

9 PIMENTEL, Sílvia. Evolução dos direitos da mulher: norma, fato, valor. São Paulo: Editora Revista dos Tribunais, 1978. p. 14.

10 CARDOSO, Irede; CARDOZO, José Eduardo Martins. Caminhos da constituinte: o direito da mulher na nova Constituição. São Paulo: Global, 1986. p. 78.

11 PIMENTEL, op. cit., p. 17.

12 Disponível em: <http://www.brasil.gov.br/secoes/mulher/cidadania-e-seguranca/rede-de-atendimento>. Acesso em: 31 jan. 2013.

13 Apelação Cível n ${ }^{\circ}$ 598362655, Oitava Câmara Cível, Tribunal de Justiça do RS, Relator: José Ataídes Siqueira Trindade, Julgado em 1-3-2000; Apelação Cível no 70012836755, Sétima Câmara Cível, Tribunal do RS, Relatora: Maria Berenice Dias. Julgado em 21-12-2005;

14 TJMG; $3^{\text {a }}$ Câm. Crim; Rec. em Sentido Estrito 1.0145.07.414517-1/001. Rel. Des ANTÔNIO CARLOS CRUVINEL. Data do Julgamento: 15-12-2009;

15 STJ, CC No 103.813/MG; CC 90767/MG; TJRS Conflito de Jurisdição nº 70041105339, Segunda Câmara Criminal, Tribunal de Justiça do RS; TJDF - RCL RCL 96029720108070000 DF 0009602-97.2010.807.0000.

16 Disponível em: http://www.senado.gov.br/noticias/lei-maria-da-penha-traz-avancos-mas-violencia-domestica-ainda-preocupa.aspx. Acesso em 31-1-2013. 
17 DIAS, Maria Berenice. A Lei Maria da Penha na Justiça: a efetividade da Lei ${ }^{\circ}$ 11.340/2006 de combate à violência doméstica e familiar contra a mulher. São Paulo: Revista dos Tribunais, 2007. p. 15.

18 STF, ADC19e ADI 4.424.

19 Disponível em: <http://www.senado.gov.br/atividade/materia/detalhes.asp?p_cod_ mate=79604>. Acesso em: 31 jan. 2013.

\section{REFERÊNCIAS}

CARDOSO, Irede; CARDOZO, José Eduardo Martins. Caminhos da constituinte: o direito da mulher na nova Constituição. São Paulo: Global, 1986.

CASTRO, Carlos Roberto de Siqueira. O princípio da isonomia e a igualdade da mulher no direito constitucional. Rio de Janeiro: Forense, 1983.

COSTA, Claudia de Lima. O sujeito no feminismo: revisitando os debates. Cadernos Pagu, Campinas, n. 19, p. 59-90, 2002.

DIAS, Maria Berenice. A Lei Maria da Penha na justiça: a efetividade da Lei $\mathrm{n}^{\circ}$ 11.340/2006 de combate à violência doméstica e familiar contra a mulher. São Paulo: Revista dos Tribunais, 2007.

GALLARDO, Helio. Teoría crítica: matriz y possibilidad de derechos humanos. Cartagena: F. Gómez, 2005.

HERMANN, Leda Maria. Maria da Penha Lei com nome de mulher: considerações à Lei $n^{0}$ 11.340/2006: contra a violência doméstica e familiar, incluindo comentários artigo por artigo. Campinas/SP: Servanda Editora, 2008.

HOBSBAWM, Eric. Era dos extremos: o breve século XX - 1914-1991. Tradução de Marcos Santarrita; revisão técnica de Maria Célia Paoli. São Paulo: Companhia das Letras, 1995.

LAURETIS, Teresa de. A tecnologia do gênero. In: HOLLANDA, Heloisa Buarque de. Tendências e impasses: o feminismo como crítica da cultura. Rio de Janeiro: Rocco, 1994. p. 206-242. 
LOURO, Guacira Lopes. Epistemologia feminista e teorização social: desafios, subversões e alianças. In: ADELMAN, Miriam; SILVESTRIN, Celsi Brönstrup (Org.). Coletânea Gênero Plural. Curitiba: Editora UFPR, 2002. p. 11-22.

PIMENTEL, Sílvia. Evolução dos direitos da mulher: norma, fato, valor. São Paulo: Editora Revista dos Tribunais, 1978.

Artigo recebido em: 10-7-2012

Aprovado em: 8-11-2013

\section{Taylisi de Souza Corrêa Leite}

Mestre em Direito pela Universidade Estadual Paulista Júlio de Mesquita Filho; professora da Uniseb-COC e da Faculdade de Educação São Luís.

Uniseb-COC, Faculdade de Direito. Rua Abrahão Issa Halack - até 669/670 Ribeirânia. CEP 14096160

Ribeirao Preto - SP. CEP. E-mail: taylisi_leite@hotmail.com

\section{Paulo César Corrêa Borges}

Pós-doutor pela Universidade de Sevilla - Espanha; mestre e doutor em Direito pela Universidade Estadual Júlio de Mesquita Filho (Unesp); professor assistente-doutor de Direito Penal e Criminologia do Departamento de Direito Público da Unesp; coordenador do Programa de Pós-Graduação em Direito da Unesp (PPGDIREITO); promotor de Justiça do Ministério Público do Estado de
São Paulo. Contato: pauloborges@ franca.unesp.br

UNESP - Faculdade de Ciências Humanas e Sociais, Departamento de Direito Público/PPGDIREITO - Av. Eufrázia Monteiro Petráglia, 900

Jardim Dr. Antônio Petráglia. CEP 14409-160 - Franca, SP - Brasil. E-mail: pauloborges@franca.unesp.br

\section{Euller Xavier Cordeiro}

Mestrando em Direitos Fundamentais pela Unesp-Franca; membro do Núcleo de Estudos Tutela Penal dos Direitos Humanos (NETPDH); advogado.

Universidade Estadual Paulista Julio de Mesquita Filho - PPGD

Av Eufrásia Monteiro Petráglia, 900 Jd Dr. Antonio Petráglia - CEP 14409-160

E-mail: eullercordeiro@yahoo.com.br 
